\title{
Penetrating keratoplasty for corneal scarring due to herpes zoster ophthalmicus
}

\author{
H KAZ SOONG, ANN E SCHWARTZ, ROGER F MEYER, AND ALAN SUGAR \\ From the Department of Ophthalmology, the WK Kellogg Eye Center, University of Michigan School of \\ Medicine, Ann Arbor, USA
}

SUMMARY We retrospectively studied the postoperative results in nine patients with corneal scarring due to herpes zoster ophthalmicus who underwent penetrating keratoplasty. This was a highly selected group that satisfied all of the following criteria: ( $a$ ) absence of active disease of the ocular surface and eyelids, $(b)$ intraocular pressure under control, and (c) absence of active keratouveitis. Penetrating keratoplasty after herpes zoster ophthalmicus may do well in patients with long preoperative quiescent periods in whom these restrictive preoperative criteria are observed.

Numerous studies have documented extensive involvement of the eye by herpes zoster ophthalmicus (HZO). Nearly every part of the eye can be affected, ${ }^{12}$ ranging from the eyelids to the retrobulbar structures, including the optic nerve. Corneal disease, occurring in more than half the cases of $\mathrm{HZO}$, is often the primary cause of loss of vision. ${ }^{3}$ Corneal involvement includes punctate epithelial keratitis, nummular anterior stromal infiltrates, sclerokeratitis, dendritiform lesions, keratouveitis, endotheliitis, serpiginous ulceration, exposure keratopathy, neurotrophic keratitis, mucous plaques, and immune disciform disease. ${ }^{23}$ Irreversible corneal scarring, neovascularisation, lipid deposition, thinning, and perforation often result.

In general most patients with herpes zoster keratopathy have been considered poor candidates for penetrating keratoplasty (PKP) because of cornea hyperaesthesia, tear abnormalities, eyelid disease, glaucoma, uveitis, and corneal vascularisation. For these reasons PKP is rarely performed after HZO. We retrospectively examined the surgical results and the associated criteria for selection of patients in nine cases of PKP after HZO.

\section{Patients and methods}

The nine cases we reviewed represent all the PKPs performed for corneal scarring due to $\mathrm{HZO}$ at the University of Michigan in the past seven years except

Correspondence to H Kaz Soong, MD, WK Kellogg Eye Center, 1000 Wall Street, Ann Arbor, MI 48105, USA. for one case that was lost to follow-up three months postoperatively. The patients ranged in age from 55 to 86 years (mean age 70 ) at the time of PKP. Six patients were female and three were male. Postoperative follow-up time ranged from 5 to 40 (mean 18) months. The diagnosis of herpes zoster keratopathy was based on the presence of antecedent skin vesicles and scarring in the ophthalmic division of the trigeminal nerve dermatome. All affected eyes had corneal stromal scarring with central involvement. Each PKP was performed on a previously ungrafted eye.

Preoperatively one patient (case 9) had mild Fuchs's corneal dystrophy and macular oedema in the affected eye. In this patient the main cause of poor vision was the severe corneal scarring due to HZO and not the mild Fuchs's dystrophy. Two patients (cases 6 and 7) had preoperative glaucoma secondary to $\mathrm{HZO}$ that was well controlled on topical antiglaucoma agents. Corneal sensations and Schirmer's test with topical anaesthetic were checked preoperatively in all patients. No eyes were noted preoperatively to have active ocular surface or eyelid disorders, such as dry eyes, exposure, rosacea, blepharitis, keratinisation, and trichiasis. No patient had uncontrolled glaucoma or active uveitis at the time of surgery. Thus these nine surgical candidates constituted a highly selected group representing roughly less than $5 \%$ of all patients with previous HZO.

Donor corneal tissue was stored in McCareyKaufman medium at $4^{\circ} \mathrm{C}$ within 15 hours after donor 
death and enucleation, and transplanted within 72 hours. During surgery the donor graft was prepared by punching from the endothelial side of the cornea on to a Teflon block with a trephine $(8.0$ to $9.0 \mathrm{~mm})$. After marking the host cornea with a trephine 0.5 $\mathrm{mm}$ smaller, the anterior chamber was entered with either the same trephine or with a razor-blade knife, and the incision was completed with corneal scissors. The donor corneal button was sutured to the host cornea with double-continuous $10-0$ and $11-0$ nylon sutures and the epithelium was left intact. Three cases (patients 1, 2, and 6) had PKP alone, while in four others (patients $3,4,5$, and 7) this was combined with extracapsular cataract extraction and posterior chamber intraocular lens implantation. The remaining two cases (patients 8 and 9) had PKP combined with anterior vitrectomy. At the completion of surgery the patients received subconjunctival injections of gentamicin and methylprednisolone. No topical eye medications were given until the first postoperative morning.

Topical prednisolone acetate $1 \%$ was then started at least three times a day, but for cases treated by PKP combined with cataract extraction topical corticosteroids were given as often as every two hours around the clock. Two patients received timolol $0.5 \%$, three received mydriatics, one received chloramphenicol $0.5 \%$, and two received artificial tears.
At each daily postoperative slit-lamp examination the epithelium on the graft was assessed with topical fluorescein and checked for defects. Postoperative rises in intraocular pressure were treated with timolol, dipivefrin, and/or acetazolamide. The patients were examined daily for up to five postoperative days until discharge from the hospital, then at one week, three weeks, and at progressively longer intervals. The diagnosis of corneal graft rejection was based on the presence in the donor cornea of keratic precipitates, endothelial rejection lines, or subepithelial infiltrates. The presence of iritis and increased graft thickness constituted an additional, but not necessary, criterion for immune rejection. Graft failure was defined as an irreversibly thick and oedematous, or a scarred and opaque, donor cornea.

\section{Results}

Seven of the nine patients had a clear graft at the end of the follow-up period ranging from 5 to 40 (mean 18 ) months. Six of the patients with clear grafts had a final visual acuity of $20 / 50$ or better. However, one patient with a clear graft (case 7) had a final visual acuity of counting fingers at 2 feet $(60 \mathrm{~cm})$ due to macular degeneration with subretinal neovascularisation. Table 1 summarises the clinical findings.

To study the significance of the preoperative quiescent period on the prognosis of the grafts we

Table 1 Clinical profile of patients

\begin{tabular}{|c|c|c|c|c|c|c|c|c|}
\hline $\begin{array}{l}\text { Patient's } \\
\text { number, } \\
\text { age, sex }\end{array}$ & $\begin{array}{l}\text { Corneal } \\
\text { sensation }\end{array}$ & $\begin{array}{l}\text { Corneal vessels, } \\
\text { central/peripheral }\end{array}$ & $\begin{array}{l}\text { Time since } \\
\text { last activity } \\
\text { (months) }\end{array}$ & $\begin{array}{l}\text { Postop. } \\
F / U \\
\text { (months) }\end{array}$ & $\begin{array}{l}\text { Preop. } \\
V A\end{array}$ & $\begin{array}{l}\text { Best } V A \text { I } \\
\text { final } V A \\
\text { (postop.) }\end{array}$ & $\begin{array}{l}\text { Graft clarity/ } \\
\text { cause for } \mid V A\end{array}$ & $\begin{array}{l}\text { Other Dx/procedures } \\
\text { in PKP eye }\end{array}$ \\
\hline $1 / \mathrm{F} / 55$ & Normal & $\begin{array}{c}-I+\text { (superficial } \\
1 \text { quadrant) }\end{array}$ & 61 & 27 & $20 / 200$ & $20 / 20 / 20 / 20$ & Clear/NA & None \\
\hline $2 / \mathrm{F} / 69$ & Marked & $-1-$ & 9 & 5 & $\mathrm{CF} 30 \mathrm{~cm}$ & $20 / 40 / 20 / 50$ & Clear/NA & Cataract/none \\
\hline $3 / \mathrm{M} / 65$ & Marked | & $\begin{array}{l}? /+(\text { superficial } \\
\text { and } 360^{\circ} \text { stromal) }\end{array}$ & 12 & 12 & $20 / 60$ & $20 / 20 / 20 / 20$ & Clear/NA & Cataract/ECCE, PC IOL \\
\hline $4 / F / 86$ & Mild | & $\begin{array}{r}+/+ \text { (stromal } \\
1 \text { quadrant) }\end{array}$ & 24 & 40 & CF $30 \mathrm{~cm}$ & $20 / 30 / 20 / 40-$ & Clear/NA & Cataract/ECCE, PC IOL \\
\hline $5 / F / 64$ & Normal & $-1-$ & 44 & 12 & $20 / 70$ & $20 / 20 / 20 / 20$ & Clear/NA & Cataract/ECCE, PC IOL \\
\hline $6 / \mathrm{M} / 56$ & Absent & $+/+\left(\right.$ stromal $\left.360^{\circ}\right)$ & 45 & 17 & $20 / 300$ & $20 / 20 / 20 / 25$ & Clear/NA & $2^{\circ}$ Glaucoma/none \\
\hline $7 / \mathrm{M} / 78$ & Absent & $\begin{array}{l}+/+ \text { (stromal } \\
2 \text { quadrants })\end{array}$ & 23 & 7 & $\mathrm{CF} 120 \mathrm{~cm}$ & $\begin{array}{l}20 / 200 / \\
\text { CF } 60 \mathrm{~cm}\end{array}$ & Clear/macular SRNV & $\begin{array}{l}\text { Cataract (glaucoma) } \\
\text { macular SRNV/ECCE, } \\
\text { PC IOL }\end{array}$ \\
\hline $8 / F / 73$ & Normal & $-1-$ & 4 & 23 & CF $180 \mathrm{~cm}$ & $20 / 30 / \mathrm{HM}$ & $\begin{array}{l}\text { Stromal and } \\
\text { microcystic oedema/ } \\
\text { graft rejection } \\
\text { leading to graft } \\
\text { failure }\end{array}$ & $\begin{array}{l}\text { Synechial angle closure, } \\
\text { glaucoma/anterior } \\
\text { vitrectomy, CCT, } \\
\text { conjunctival flap }\end{array}$ \\
\hline 9/F/80 & Marked I & $\begin{array}{l}-1+\text { (superficial } \\
1 \text { quadrant) }\end{array}$ & 11 & 5 & $\mathrm{CF} 30 \mathrm{~cm}$ & $\begin{array}{l}20 / 30 / \\
\text { CF } 90 \mathrm{~cm}\end{array}$ & $\begin{array}{l}\text { Failed/graft failure due } \\
\text { to rejection }\end{array}$ & $\begin{array}{l}\text { Cataract, RPE atrophy } \\
\text { small disc/anterior } \\
\text { vitrectomy PAS lysis, } \\
\text { AC IOL }\end{array}$ \\
\hline
\end{tabular}

$\mathrm{F} / \mathrm{U}=$ follow-up; $\mathrm{VA}=$ visual acuity; $\mathrm{Dx}=$ diagnoses; $\mid=$ =decrease; $\mathrm{NA}=$ not applicable; $\mathrm{ECCE}=$ extracapsular cataract extraction; $\mathrm{PC}=$ posterior chamber; $\mathrm{AC}=$ anterior chamber; $\mathrm{IOL}=$ intraocular lens; $\mathrm{CF}=$ counting fingers; $\mathrm{HM}=$ hand motions, $2^{\circ}=$ secondary; SRNV=subretinal neovascularisation; $P B K=$ pseudophakic bullous keratopathy; $C C T=$ cyclocryotherapy; $R P E=$ retinal pigment epithelium; PAS = peripheral anterior synechiae. 
determined the time interval from the acute disease (active HZO) to the time of PKP in each case. This interval ranged from 4 to 112 (mean 39) months. The only two cases that ended in graft failure (patients 8 and 9) had shorter quiescent periods of 4 and 11 months. In both cases graft failure was preceded by immune rejection. Patient 2 underwent PKP after only nine months of quiescence and died after five months of postoperative follow-up; however, the graft remained clear at the time of her death. All other patients with clear grafts had a longer preoperative quiescent period of 23 to 112 months.

The status of preoperative corneal sensation did not correlate with postoperative graft clarity, rejection, or failure (Table 1). Among the seven patients with clear grafts corneal sensation varied preoperatively from briskly intact (cases 1 and 5), mildly decreased (case 4), markedly decreased (cases 2 and 3), to absent (cases 6 and 7). Among the two patients with grafts that underwent immune rejection and eventually failed one (case 8 ) had intact sensation preoperatively and one (case 9) had markedly decreased sensation.

Preoperative corneal vascularisation was present in six of nine patients and was not correlated with postoperative immune graft rejection. Of these six cases three had superficial corneal vessels (cases 1,2, and 9) and three had stromal vessels (cases 4, 6, and 7). Of the two patients who had graft rejection one (case 9) had some superficial peripheral vessels preoperatively, while the other (case 8 ) had no vascularisation.

In all nine cases the epithelium healed completely over the donor cornea within a few days after PKP. No epithelial defects lasted longer than one week, and no patients experienced recurrent epithelial breakdown following the immediate postoperative period.

\section{Discussion}

Keratopathy secondary to $\mathrm{HZO}$ is a rare indication for PKP in many large reported series. In a study from the Wilmer Ophthalmological Institute which consisted of 1057 consecutive PKPs from 1941 through 1973 only three were for zoster keratopathy. ${ }^{4}$ Similarly, of the 710 consecutive PKPs done between 1947 and 1978 at the Estelle Doheny Eye Foundation only three were for zoster keratopathy. ${ }^{5}$ Our own experience at the WK Kellogg Eye Center shows that only 10 out of 1359 consecutive PKPs from 1980 through 1985 were for keratopathy due to HZO. The paucity of PKPs done for this indication reflects the widespread understanding that most $\mathrm{HZO}$ patients are poor candidates for PKP owing to a neurotrophic cornea, recurrent or chronic inflammation, corneal vascularisation, glaucoma, hypotony, decreased blink frequency, poor viability of corneal epithelium, and disease of the ocular surface, including tear and eyelid abnormalities. ${ }^{36-8}$ Marsh $^{7}$ indicated further that vascularisation of the cornea may be correlated with an increased incidence of post-PKP immune rejection. Many previous reports have specifically cautioned against PKP for HZO for these reasons..$^{6910}$ In cases on which we are forced to operate while the eye is actively inflamed (for example, corneal perforation) or in cases of corneal scarring limited to the anterior stroma we prefer lamellar keratoplasty over PKP as a safer procedure.

Our series shows that long-term graft clarity and visual prognosis for zoster keratopathy is improved by the following: (1) longer quiescent waiting period between active disease and surgery, and (2) selection of eyes with minimal preoperative disorders of the ocular surface or neuroretinal or intraocular disease. The later criteria in general skew the selection towards eyes with milder damage due to HZO. Preoperative corneal anaesthesia and vascularisation are of concern and warrant extra attention but did not appear to have any effects in this series.

The present series of nine patients is small owing to the highly selective preoperative criteria. Our experience nevertheless indicates that PKP for zoster keratopathy is not necessarily associated with a dismal prognosis. With fastidious preoperative selection criteria many of the grafted eyes may do quite well in this select group of patients.

The authors thank John Yoon, MD, for his assistance.

\section{References}

1 Edgerton AE. Herpes zoster ophthalmicus: report of cases and review of literature. Arch Ophthalmol 1945; 34: 40-62, 114-53.

2 Womack LW, Liesegang TJ. Complications of herpes zoster ophthalmicus. Arch Ophthalmol 1983; 101: 42-5.

3 Liesegang TJ. Corneal complications from herpes zoster ophthalmicus. Ophthalmology 1985; 92: 316-24.

4 Arentsen JJ, Morgan B, Green WR. Changing indications for keratoplasty. Am J Ophthalmol 1976; 81: 313-8.

5 Smith RE, McDonald HR, Nesburn AB, Minckler DS. Penetrating keratoplasty-changing indications, 1947 to 1978. Arch Ophthalmol 1980; 98: 1226-9.

6 Raber I, Laibson PR. Herpes zoster ophthalmicus. In: Liebowitz HM, ed. Corneal disorders. 1st ed. Philadelphia: Saunders, 1984: 411-9.

7 Marsh RJ. Current management of ophthalmic herpes zoster. Trans Ophthalmol Soc UK 1976; 96: 334-7.

8 Marsh RJ. Herpes zoster keratitis. Trans Ophthalmol Soc UK 1973; 93: 181-92.

9 Pavan-Langston D. Viral diseases. In: Smolin G, Thoft RA, eds. The cornea. 1st ed. Boston: Little, Brown, 1983: 178-95.

10 Marsh RJ. Ophthalmologic herpes zoster. In: Darnell RW, ed. Viral diseases of the eye. 1st ed. Philadelphia: Lea and Feibiger, 1985: 78-96.

Accepted for publication 15 October 1987. 